\title{
Comparative study of nutritional and economical parameters of silkworm (Bombyx mori) treated with silver nanoparticles and Spirulina
}

\author{
Thangapandiyan $\mathrm{S}^{*}$ and R. Dharanipriya
}

\begin{abstract}
Background: Sericulture depends on rearing of silkworm on mulberry leaves. For this reason, Silk production has direct relationship with larval growth. One of the alternative ways of improvement of larval growth and cocoon production is enrichment of mulberry leaves with supplementary nutrients. The present study has been aiming to find out the feed efficacy of silver nanoparticles (AgNPs) and Spirulina-treated $M R_{2}$ mulberry leaves with regard to food utilization by larvae and ultimate impact on the economic parameters of silkworm (Bombyx mori).

Result: Fresh mulberry leaves were treated with chemically mediated AgNPs and Spirulina; it was diluted by different concentrations such as 100 ppm AgNPs $\left(T_{2}\right), 300$ ppm AgNPs $\left(T_{3}\right), 500$ ppm AgNPs $\left(T_{4}\right)$, AgNPs with Spirulina $\left(T_{5}\right)$, and Spirulina alone $\left(T_{6}\right)$. Group $T_{1}$ served as the control. The result indicates significant differences among the six groups. The economic traits and the nutrient efficacy were significantly increased in AgNPs and Spirulina-treated groups when compared to those in the control.

Conclusion: Silkworms are the only source for producing silk. Commercial AgNPs and Spirulina administration has significantly induce food consumption, utilization, and superior cocoon characters by maintaining a balance in the gut flora. Thus, it is inferred that silkworm larvae fed with commercial AgNPs and Spirulina beneficially influence the energy and economic parameters of B. mori, which can be exploited in commercial cocoon production.
\end{abstract}

Keywords: Silkworm (Bombyx mori), Silver nanoparticles, Spirulina, Growth

\section{Background}

The silkworm Bombyx mori rearing is a traditional business in Asia. Silk is "The Queen of Fibers" which provides an excellent environment for microorganisms to reproduce because of their large surface area and ability to retain moisture in the grids of fabrics (Guangyu, Yan, Xiaoliang, \& Yuyue, 2014). Silk is a protein-based biopolymer which contains a hydrophobic structural protein termed fibroin coated by a glue-like coating protein called sericin (Hardy, Romer, \& Scheibel, 2008). A higher rate of protein synthesis was reported in the fatbody (Martin, Kinner, \& Thomas, 1971), and it seems to act as the storage organ for a variety of proteins and facilitate their

\footnotetext{
* Correspondence: stp.nano@gmail.com

Department of Zoology, PSG College of Arts and Science, Coimbatore, Tamilnadu, India
}

migration to other tissues during metabolism. Tuigong, Kipkurgat, \& Madara (2015) examined the activity of silk production which is enriched by the large Morus alba mulberry production in sericulture practices in widespread areas leading to promising effects on silkworm rearing and cocoon production. Traditional rearing on mulberry leaf (the regular food of the monophagous silkworm) amplified larval efficiency in renovating food, and high silk production was achieved when the traditional mulberry leaf was added with artificial diet (Alessio et al., 2014). The enrichment of mulberry leaves with the aim of increasing the production of cocoon is a very important aspect (Islam, Ali, Paul, Sultana, \& Banu, 2004).

Among the novel metals, silver and its derivatives have long been used as antimicrobial agents. After bacterial discovery, silver and silver salts were recognized for their 
antibacterial property (Marek, Tatsiana, Aleksandra, \& Lidia, 2016). Silver nanoparticles exhibit new optical properties, which are observed neither in molecules nor in bulk metals (Asta, Igoris, Puiso, Algimantas, \& Asta, 2006). Ag nanoparticles can be synthesized using various methods: chemical and electro chemical (Vorobyova, Lesnikovich, \& Sobal, 1999). Chemical reduction is the most frequently adopted method for the synthesis of silver nanoparticles (AgNPs) as colloidal silver dispersion in water is stable. The reduction of silver ions in aqueous solution generally yields colloidal silver with the size of particles being several nanometers in diameter (Aashritha, 2013).

Silkworms obtain its entire nutritional requirement from mulberry leaves because this insect is monophagous and can complete its life cycle on mulberry leaves entirely (Seki \& Oshikane, 1959). Generally, vitamins present in the mulberry leaves fulfill the minimum needs of silkworms but the amount of vitamins present in mulberry leaves diverges on the basis of environmental conditions, usage of fertilizers in field and mulberry varieties, and other field practices (Ito, 1978). B. mori involves precise essential sugars, amino acids, proteins, and vitamins for its normal growth and survival and also for the silk gland activity and growth (Sengupta, Singh, \& Mustafi, 1972). Akhtar and Asghar (1972) have initiated that vitamins and mineral salts played an important role in the nutrition of silkworm. Spirulina-mediated activation of tissue metabolism seems to be an essential factor for promotion of biological parameters of silk gland of silkworm larvae. The present study has been aimed to find out the feed efficacy of AgNP-treated MR2 mulberry leaves with regard to food utilization by larvae and ultimate impact on the cocoon parameters of silkworm so as to spot out the most nutritive one for bivoltine silkworm in Tamil Nadu climatic conditions.

\section{Materials and methods Materials}

Bivoltine hybrid silkworm Bombyx mori, plastic rearing boxes, nylon net, iron stand, ant wells, ruler scale, weighing electrical balance, silver nitrate $\left(\mathrm{AgNO}_{3}\right)$, trisodium citrate $\left(\mathrm{C}_{6} \mathrm{H}_{5} \mathrm{O}_{7} \mathrm{Na}_{3}\right)$, and double-distilled water were used throughout the experiment. The chemical used in this study was purchased from Hi media laboratory, New Delhi.

\section{Rearing of mulberry silkworm Bombyx mori}

The third-instar larvae of Indian bivoltine hybrid silkworm Bombyx mori were collected from chawki worm rearing center, Kethanur, Tamil Nadu, India. The larvae were divided into 6 experimental groups including the control, each group consisting of 15 larvae. The larvae were reared in plastic boxes measuring $15 \times 15 \times 5 \mathrm{~cm}$ covered with nylon net and placed in an iron stand with ant wells. The control and treated MR2 mulberry leaves were fed to silkworms, four times per day $(6 \mathrm{am}, 10 \mathrm{am}, 3 \mathrm{pm}$, and $10 \mathrm{pm})$. They were maintained up to the cocoon stage.

\section{Fabrication of silver nanoparticles}

The silver nanoparticles were synthesized using chemical reduction method (Thangapandiyan \& Prema, 2012). In this method, $150 \mathrm{ml}$ of $1 \times 10^{-3} \mathrm{M} \mathrm{AgNO}_{3}$ solution was heated to boiling. To this solution, $5 \mathrm{ml}$ of $1 \%$ trisodium citrate was added drop by drop. During this process, the solution was mixed vigorously. Reaction mixture was heated until the color changes from colorless to pale yellow. Then, it was removed from the heating element and stirred until cooled to room temperature.

Mechanism of reaction could be expressed as follows:

$4 \mathrm{Ag}^{+}+\mathrm{C}_{6} \mathrm{H}_{5} \mathrm{O}_{7} \mathrm{Na}_{3}+2 \mathrm{H}_{2} \mathrm{O} \rightarrow 4 \mathrm{Ag}^{0}+\mathrm{C}_{6} \mathrm{H}_{5} \mathrm{O}_{7} \mathrm{H}_{3}+3 \mathrm{Na}^{+}$ $+\mathrm{H}^{+}+\mathrm{O}_{2} \uparrow$

The solution was washed three times in double-distilled water and once in ethanol solution. The supernatant of the reaction solution was discarded, and particles were dried in hot air oven at $60^{\circ} \mathrm{C}$. The dried particles were used for further analysis.

\section{Preparation of Spirulina solution}

Spirulina powder was purchased from Twenty First Century pharmaceuticals Pvt. Ltd., Chennai, and the experimental dose for $300 \mathrm{ppm}$ concentration was prepared.

\section{Mulberry leaves treated with silver nanoparticles and Spirulina}

Different concentrations of AgNPs (100 ppm, 300 ppm, $500 \mathrm{ppm})$, AgNPs with Spirulina, and Spirulina alone were prepared. Fresh MR2 mulberry leaves were separately soaked in these concentrations for $15 \mathrm{~min}$ and then were dried in air for $10 \mathrm{~min}$. The treated mulberry leaves were used to feed the third-, fourth-, and fifth-instar larvae of the silkworm Bombyx mori. They were maintained up to the cocoon stage.

\section{Characterization of silver nanoparticles}

The fabricated silver nanoparticles were confirmed by optical measurement using Shimadzu dual beam spectrophotometer (UV-2000) in the wavelengths ranging between 200 and $800 \mathrm{~nm}$ at the resolution of $1 \mathrm{~nm}$. The morphological characterization of the prepared AgNPs was observed by scanning electron microscopy (JSM 35 CF JEOL) operated at a resolution of $60 \mathrm{~A}^{\circ}$ at $15 \mathrm{kv}$ magnification of $5.0 \mathrm{k}$. The scale was about $32 \mathrm{~mm}$. Confirmation of elemental silver in the synthesized nanoparticles was carried out by EDS instrument (JSM 35 CF JEOL) in a resolution of $60 \AA$, operated at $15.0 \mathrm{kV}$ with a magnification of about $5 \mathrm{k}$. 


\section{Estimation of nutritional traits}

The nutrigenetic traits estimation study was carried out in the fifth-instar larvae. Silkworm rearing was accompanied by a standard method under the acclaimed temperature and relative humidity until the fourth molt. On the first day of the fifth instar, from the entire 90 larvae, five healthy silkworms in each group were selected for estimation on nutritional traits analysis. Accurately weighed fresh mulberry leaves were fed five times a day to the experimental group and the control. Simultaneously, daily increases in larval weight were recorded separately. Silkworm rearing continued using appropriate plastic trays. The healthy larvae were counted daily in each group. Left over leaves and excreta were collected on each subsequent day, separated manually, and dried in a hot air oven daily at about $100^{\circ} \mathrm{C}$ until they reached a constant weight using an air-tight electronic balance. When the larvae finished feeding, they were shifted to the mountage for spinning at normal ambient temperature of $25 \pm 2{ }^{\circ} \mathrm{C}$ and $\mathrm{RH} 65 \pm 5 \%$. Cocoons were harvested 4-5 days later after completion of cocoon spinning. Harvested cocoons were retrieved for quantitative traits using the equations detailed below. The dry weight of leftover leaves, excreta, larvae, cocoon, and shell in each treatment was recorded.

During the silkworm nutritional study, data were collected on the biomass of larvae and cocoons for the 19 nutrigenetic traits on ingesta, digesta, excreta, approximate digestibility $(A D)$, reference ratio $(R R)$, consumption indices $(\mathrm{CI})$, relative growth rate (RGR), respiration and metabolic rate (MR), and efficiency conversion of ingesta (ECI) and digesta (ECD) for larva, cocoon, and shell. Further, the ingesta and digesta required for producing $1 \mathrm{~g}$ of cocoon and shell (I/g and D/g) were collected and calculated as described by standard gravimetric methods.

The equations with brief description of the nutrigenetic traits evaluated are given below (Ramesha, Lakshmi, Kumari, Anuradha, \& Kumar, 2012).

$$
\begin{aligned}
\text { Ingesta }(\mathrm{g})= & \text { Dry weight of leaf fed } \\
& - \text { Dry weight of left over leaf } \\
\text { Digesta }(\mathrm{g})= & \text { Dry weight of leaf ingested } \\
& - \text { dry weight of litter }
\end{aligned}
$$

\section{Approximate digestibility (\%)}

This directly indicates the assimilation efficiency of mulberry leaves and depends on the passage rate of food through gut in silkworm

$$
\mathrm{AD}=\text { Dry weight of Digesta/Dry weight of food ingested } \mathrm{x} 100
$$

\section{Reference ratio}

This is an indirect expression of absorption and assimilation of food and expresses the ingesta required per unit excreta produced
$R R=$ Dry weight of food ingested/Dry weight of excreta

\section{Consumption index \\ $\mathrm{CI}=$ Ingesta $/ 5^{\text {th }}$ stage mean fresh larval weight $(\mathrm{g})$ $\times 5^{\text {th }}$ stage larval duration in days}

\section{Relative growth rate}

Refers to larval gain biomass and indicates the efficiency of conversion of nutrition into larval biomass.

$$
\begin{aligned}
\mathbf{R G R}= & \frac{\text { Weight gain of the larva during feeding period }}{5 \text { th stage mean fresh larval weight }(\mathrm{g})} \\
& \times 5^{\text {th }} \text { stage larval duration in days }
\end{aligned}
$$

\section{Respiration}

A catabolic reaction in which total oxidation of the digested or assimilated food for releasing energy required for the entire biological activities by break down of macromolecules into simpler molecules

$$
\begin{aligned}
\text { Respiration }= & \text { Dry weight of food digested } \\
& - \text { Maximum dry weight of larvae }
\end{aligned}
$$

\section{Metabolic rate}

Measure of total biochemical reactions involving both catabolic and anabolic reactions of an organism, associated with the degradation of macromolecules into smaller unit and vice versa

$$
\begin{aligned}
\mathrm{MR}= & \text { Respiration } / 5^{\text {th }} \text { stage mean fresh larval weight }(\mathrm{g}) \\
& \times 5^{\text {th }} \text { stage larval duration in days }
\end{aligned}
$$

\section{ECI/ECD to larva (\%)}

The expression of efficiency conversion of ingesta and digesta into larval biomass

$$
\begin{aligned}
\mathrm{ECI} / \mathrm{ECD} \text { to larva } & =\frac{\text { dry weight gained by larvae during feeding period }}{\text { dry weight of ingesta or digesta }} \\
& \times 100
\end{aligned}
$$

Efficiency conversion of ingesta/efficiency conversion of digesta (ECI/ECD)

\section{$\mathrm{ECI} / \mathrm{ECD}$ to cocoon (\%)}

This is the most economically important trait used by the sericulture industry. It was the expression of efficiency conversion of ingesta and digesta into the cocoon, also referred to as the leaf-cocoon conversion rate. This nutrigenetic trait was kept as the ultimate index for assessing the superiority of group for nutritional efficiency in this investigation 
$\mathrm{ECI} / \mathrm{ECD}$ to cocoon $=\frac{\text { dry weight of cocoon }}{\text { dry weight of food ingested or digested }} \times 100$

Efficiency conversion of ingesta/efficiency conversion of digesta (ECI/ECD)

\section{Ingesta required producing $1 \mathrm{~g}$ of cocoon/cocoon shell}

This was another important trait of profitable significance to assess silkworm breed performance in nutrigenetic analysis. It was the expression of total ingesta required for the production of $1 \mathrm{~g}$ of cocoon

Ingesta/g cocoon/shell

$=$ Dry weight of Ingesta/Dry cocoon or cocoon shell weight

\section{Digesta required producing $1 \mathrm{~g}$ of cocoon / cocoon shell}

The total digesta requisite for the production of 1 gram of cocoon and shell

Digesta/g cocoon/shell

$=$ Dry weight of Digesta/Dry cocoon or cocoon shell weight

\section{Analysis of economic traits}

Five days after spinning, the cocoons were harvested. About five cocoons from each group were taken for analysis of their economic traits.

\section{Length and weight of silkworm}

Five larvae were randomly selected in each group and the larval weight was measured using electronic balance, and it was expressed in grams (g). The lengths of the third-, fourth-, and fifth-instar larvae were measured using a ruler scale, and it was expressed in centimeter $(\mathrm{cm})$.

\section{Weight of silk gland}

At the end of the fifth instar, when the larvae stopped eating and emptied their gut, five larvae were randomly selected from each group and anesthetized with water. The silk glands were removed and washed thoroughly with water. The weight of the silk glands was measured in each group separately.

\section{Weight of cocoon}

Five days after spinning, the cocoons were harvested and weighed using electronic balance.

\section{Weight of pupae}

After taking the cocoon weight, the cocoon was cut open and the pupal weight was measured.

\section{Cocoon shell ratio}

It is the ratio between the weight of the shell, and the whole weight of the cocoon expressed as percentage. It is calculated by using this formula (Rajitha \& Savithri, 2015)

$$
\text { cocoon shell ratio }(\%)=\frac{\text { cocoon shell weight }}{\text { cocoon weight }} \times 100
$$

Cocoon shell ratio helps to estimate the raw silk yield as well as the price of the cocoons. The ratio is altered based on the cocoon age.

\section{Length of silk filament}

About four cocoons from each group was taken and immersed in hot water $\left(65-75^{\circ} \mathrm{C}\right)$ for $10 \mathrm{~min}$. The tightly spun thread became loose. The silk filament was reeled out using a handy reeling machine "Epprouvette", and the total length for each cocoon was measured being expressed in meters ( $\mathrm{m})$, and also, the filament is weighed. It can be estimated by using the following formula (Rajitha \& Savithri, 2015)

Silk filament length $(\mathrm{m})$

$$
=\text { Revolutions of epprouvette X Wheel circumference }(\mathrm{m})
$$

\section{Estimation of sericin and fibroin content}

After the completion of the spinning, the cocoons were collected and opened to remove the pupae. The shells were dried at $80{ }^{\circ} \mathrm{C}$ and weighed. The cocoon shell were treated with $0.5 \% \mathrm{KOH}$ for $6 \mathrm{~h}$ and thoroughly washed in hot water. The following formulae were used to estimate the sericin and fibroin content (Mondal, Kanika, \& Nirmal, 2007)

Sericin content $=$ Dry weight of cocoon

-Dry weight of cocoon after alkali treatment

Fibroin content $=$ Dry weight of cocoon-Sericin content

\section{Statistical analysis}

SPSS 20 version were used for the determination of Duncan's multiple range test (DMRT), correlation, and mean \pm standard deviation

\section{Result}

Rearing of mulberry silkworm Bombyx mori

The third-instar larvae of Indian bivoltine hybrid silkworm Bombyx mori were collected from chawki worm rearing center, kethanur, Tamil Nadu, India. The larvae were divided into six groups: they were named as control $\left(\mathrm{T}_{1}\right)$, treated with AgNPs of $100 \mathrm{ppm}\left(\mathrm{T}_{2}\right), 300 \mathrm{ppm}\left(\mathrm{T}_{3}\right), 500$ ppm $\left(\mathrm{T}_{4}\right)$, AgNPs with Spirulina $\left(\mathrm{T}_{5}\right)$, and Spirulina $\left(\mathrm{T}_{6}\right)$.

\section{Fabrication of silver nanoparticles}

Silver nanoparticles were synthesized by chemical reduction method, silver nitrate as precursor and trisodium citrate as reducing agent. 


\section{Characterization of silver nanoparticles}

UV spectra of colloidal solution of silver nanoparticles showed strong absorption peak at $422 \mathrm{~nm}$ (Fig. 1). The silver nanoparticles exhibit an intense absorption peak due to the surface plasmon around $422 \mathrm{~nm}$ which really indicates the formation of silver nanoparticles. Scanning electron micrograph revealed that the particles were more or less spherical in nature (Fig. 2). The synthesized AgNPs appeared as individual particles as well as agglomerated particles. The agglomeration is due to the intermolecular force. Energy-dispersive spectrum of silver nanoparticles showed a strong signal at $3 \mathrm{KeV}$ in the silver region, and this confirmed the presence of silver nanoparticles. The elemental analysis revealed that the silver was the major constituent (Table 1)

\section{Estimation of nutritional traits}

Considerable variation was found for 12 nutrigenetic traits among the various test groups. Ingesta, digesta, approximate digestibility, and reference ratio were calculated for all the experimental groups (Fig. 3). Among the different experimental groups, the minimum ingesta $(27 \mathrm{~g})$ was obtained in the AgNPs with Spirulina-treated group followed by the Spirulina ( $29 \mathrm{~g})$ alone-treated group $\left(\mathrm{T}_{6}\right)$ and AgNPs alone-treated groups. The maximum digesta $(25.5 \mathrm{~g})$ was obtained in the AgNPs with Spirulina-treated group followed by the Spirulina $(23.5 \mathrm{~g})$ alone-treated group $\left(\mathrm{T}_{6}\right)$ and AgNPs alone-treated groups.

The maximum approximate digestibility as well as the reference ratio was exhibited in the AgNPs with Spirulina group $\left(\mathrm{T}_{5}\right)$ followed by the Spirulina alone group $\left(\mathrm{T}_{6}\right)$. Approximate digestibility nearly double the time increased in AgNPs with Spirulina (57.95\%) group $\left(\mathrm{T}_{5}\right)$ when compared to that in the control $(29.63 \%)$ group $\left(\mathrm{T}_{1}\right)$. AgNPs alone-treated group also exhibited moderate approximate digestibility $(45.71 \%)$ and the reference ratio (1.84). Consumption index was calculated for all the groups compared with the control. The minimum consumption index $(3.78 \mathrm{~g})$ was observed in the AgNPs with Spirulina-treated group $\left(\mathrm{T}_{5}\right)$, and AgNP-treated group $\left(\mathrm{T}_{4}\right)$ exhibited 3.89 consumption indexes. These two groups exhibited reduced consumption indexes than other groups. Relatively low respiration rate was found in the AgNPs with Spirulina (5.59)-treated group $\left(\mathrm{T}_{4}\right)$ than that in the control (11.23) group $\left(\mathrm{T}_{1}\right)$. The observed relative growth $(0.042)$ was high in the $\left(\mathrm{T}_{4}\right)$ group than in the control $(0.040)$ group $\left(\mathrm{T}_{1}\right)$. Metabolic rate was also the lowest in the AgNPs with Spirulina (0.77)-treated group $\left(\mathrm{T}_{4}\right)$ than in the control (0.99) group $\left(\mathrm{T}_{1}\right)$ (Fig. 4). The efficiency of mulberry leaf ingested and digested in conversion to silkworm larval biomass varied prominently among the experimental groups. The highest efficiency conversion of ingesta and digesta to larval biomass was obtained in the AgNPs with Spirulina (1.06)-treated group $\left(\mathrm{T}_{5}\right)$ followed by 300 ppm (1.05), 500 ppm (1.0), Spirulina (0.80). The highest efficiency of conversion to cocoon was obtained in AgNPs with Spirulina (1.73)-treated group $\left(\mathrm{T}_{5}\right)$ while the lowest value found in the control (1.03) group $\left(T_{1}\right)$.

The correlation coefficient between ECI/ECD cocoon and ECI/ECD larva revealed that there is a positive correlation (0.6651) between AgNPs with Spirulina-treated group against the control. The lowest ingesta required producing $1 \mathrm{~g}$ of cocoon and shell was found in AgNPs



Fig. 1 UV Visible spectrum of chemically synthesized silver nanoparticles 


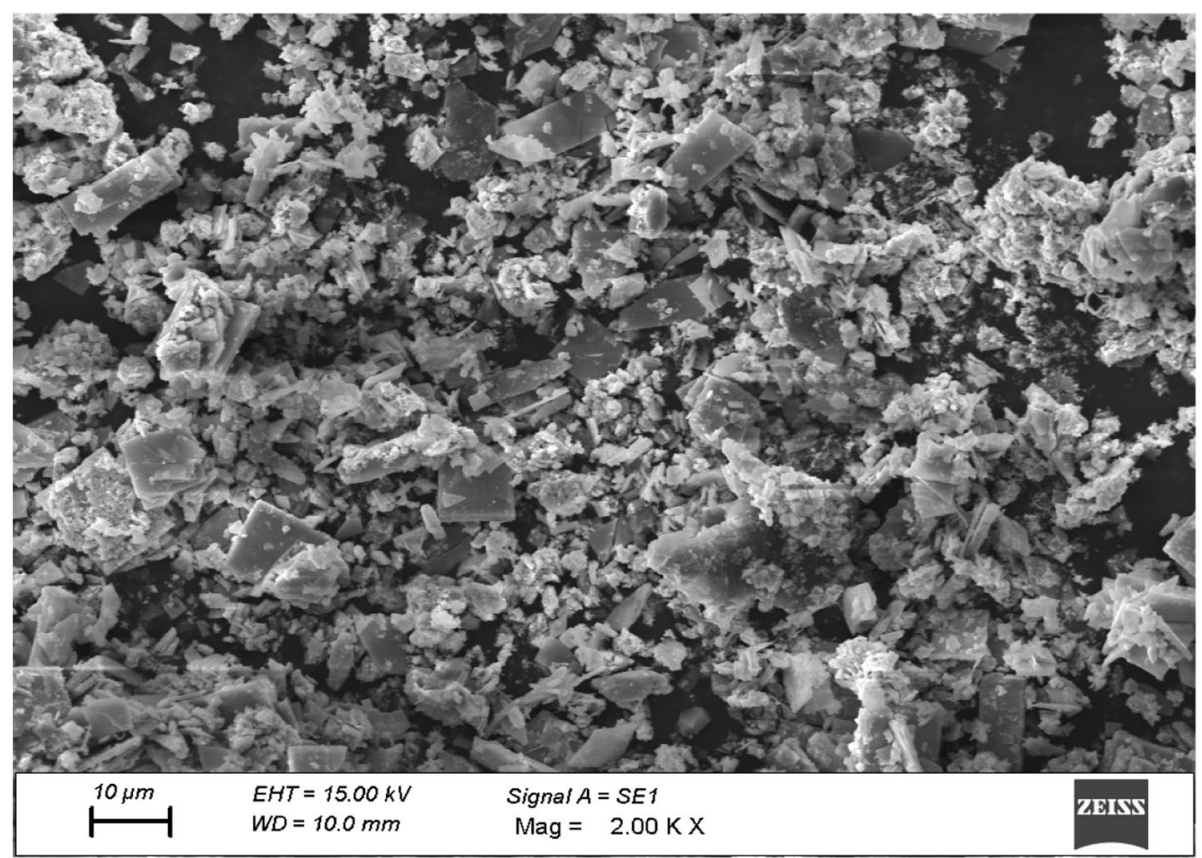

Fig. 2 Scanning electron micrograph of chemically synthesized silver nanoparticles

with Spirulina (20.11)-treated group $\left(\mathrm{T}_{5}\right)$ than in the control (25.73) group $\left(\mathrm{T}_{1}\right)$. Similarly, the amount of digesta required to produce $1 \mathrm{~g}$ of cocoon and shell was minimum at $500 \mathrm{ppm}$ AgNPs (6.45)-treated group $\left(\mathrm{T}_{5}\right)$ when compared to the Spirulina (13.86)-treated group $\left(\mathrm{T}_{6}\right)$. The correlation coefficient between $\mathrm{I} / \mathrm{g}$ cocoon/shell and D/G cocoon/shell revealed that there is a strong positive correlation (0.7921) between AgNPs with Spirulina-treated group against the control.

\section{Analysis of economic traits}

Five days after spinning, the cocoons were harvested. About four cocoons from each group were taken for analysis of their economic traits. Economic traits like cocoon weight, pupae weight, cocoon shell ratio (\%), filament length, sericin and fibroin content, and silk gland were analyzed.

\section{Silkworm growth}

The larval growth rate of silkworm Bombyx mori is given in the Table 2. The initial length and weight of the third-instar larvae was $1.7 \mathrm{~cm}$ and $1.0 \mathrm{~g}$. The recorded length and weight was gradually increased up to the

Table 1 Elemental analysis of chemically synthesized AgNPs

\begin{tabular}{llll}
\hline Nanoparticle & Element & Weight (\%) & Atomic (\%) \\
\hline Chemically synthesized silver & $\mathrm{O}$ & 20.9 & 64.05 \\
& $\mathrm{Ag}$ & 79.1 & 35.95 \\
& Total & 100 & 100 \\
\hline
\end{tabular}

fifth-instar larvae. In the control group $\left(\mathrm{T}_{1}\right)$, the length of the silkworm increased from 1.7 to $4.9 \pm 0.05 \mathrm{~cm}$. Among AgNPs alone-treated groups $\left(\mathrm{T}_{2}, \mathrm{~T}_{3}, \mathrm{~T}_{4}\right) 500 \mathrm{ppm}$ AgNP-treated group $\left(\mathrm{T}_{4}\right)$ attained the length $6 \pm 0.05 \mathrm{~cm}$, whereas AgNPs with Spirulina-treated group $\left(\mathrm{T}_{5}\right)$ attained $6.2 \pm 0.09 \mathrm{~cm}$. Spirulina alone-treated group $\left(\mathrm{T}_{5}\right)$ attained $6.1 \pm 0.03 \mathrm{~cm}$. Among all the six groups, the length of the silkworm was significantly increased in the group treated with AgNPs with Spirulina. DMRT analysis for length and weight is given in Table 3. The data shows that the AgNPs with Spirulina-treated group shows the highest significance in growth rate. So, the nutritional status will be rich in the group which is treated with AgNPs with Spirulina.

\section{Silk gland weight}

The weight of the silk gland influences the silk filament length as well as good quality of the cocoon. The weight of silk gland recorded in the present experiment was $0.75 \mathrm{~g}, 0.77 \mathrm{~g}, 0.77 \mathrm{~g}, 0.80 \mathrm{~g}, 0.87 \mathrm{~g}$, and $0.85 \mathrm{~g}$ for groups $\mathrm{T}_{1}, \mathrm{~T}_{2}, \mathrm{~T}_{3}, \mathrm{~T}_{4}, \mathrm{~T}_{5}$, and $\mathrm{T}_{6}$, respectively. Among the six groups, the $\mathrm{T}_{5}$ (AgNPs with Spirulina) group produced the maximum weight $(0.87 \mathrm{~g})$, whereas the minimum was attained in the control group $\left(\mathrm{T}_{1}\right)$.

\section{Cocoon weight}

In this study, the maximum weight $(1.84 \mathrm{~g})$ of the cocoon was obtained for the $T_{5}$ group. In this group, mulberry leaves were treated with AgNPs with Spirulina. Next to it, the $\mathrm{T}_{4}$ group produced $1.71 \mathrm{~g}$ cocoon weight. The control group produced the minimum cocoon weight $(1.30 \mathrm{~g})$. 


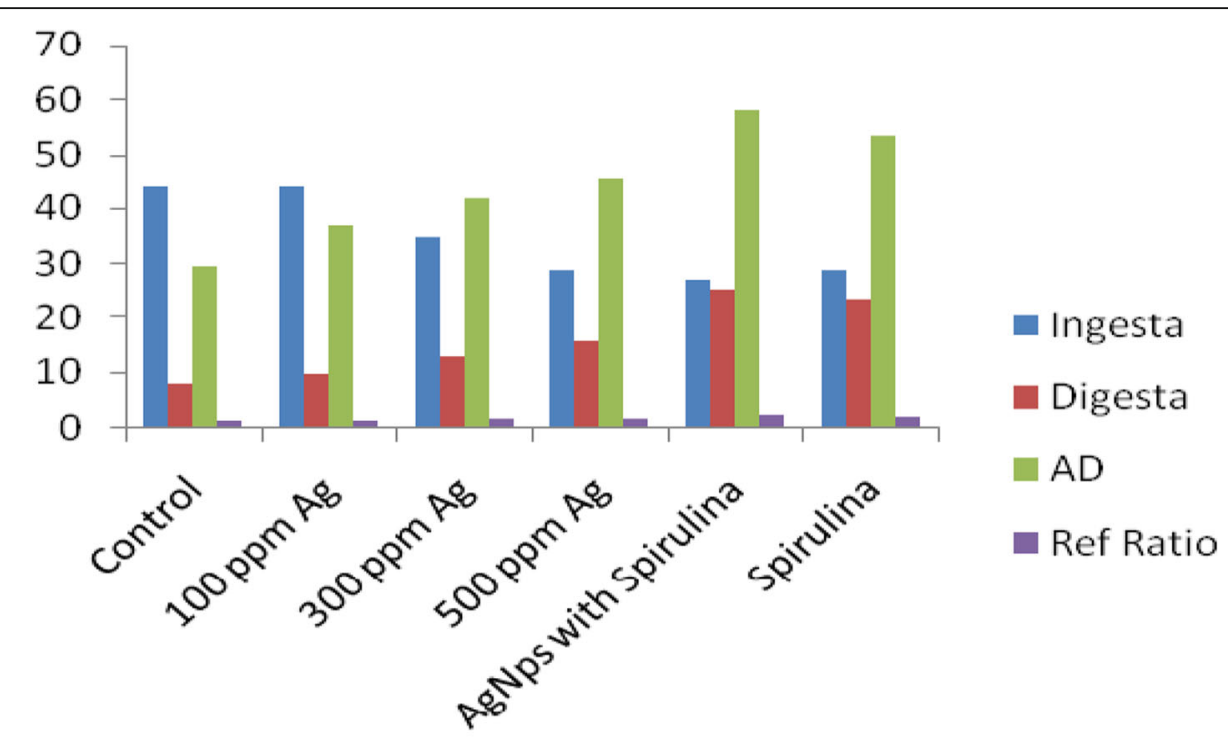

Treatment

Fig. 3 Comparison of ingesta, digesta, approximate digestibility, and reference ratio of treated silkworm groups

\section{Pupae weight}

Weight of the pupae was at maximum $(1.22 \mathrm{~g})$ in the $\mathrm{T}_{6}$ group. In this group, the leaves were treated with Spirulina solution alone.

\section{Cocoon shell ratio (\%)}

Cocoon shell ratio was calculated for all the groups. It was represented in percentage (\%). It was found to be at maximum $(41.3 \%)$ in the $\mathrm{T}_{5}$ group. In this group, mulberry leaves were treated with AgNPs with Spirulina (Fig. 5).

\section{Filament length and filament weight}

The length and weight of the silk filament produced by the larvae was positively increased in all the treated groups. Among all the test groups, the AgNPs with Spirulina-treated group produced the maximum filament

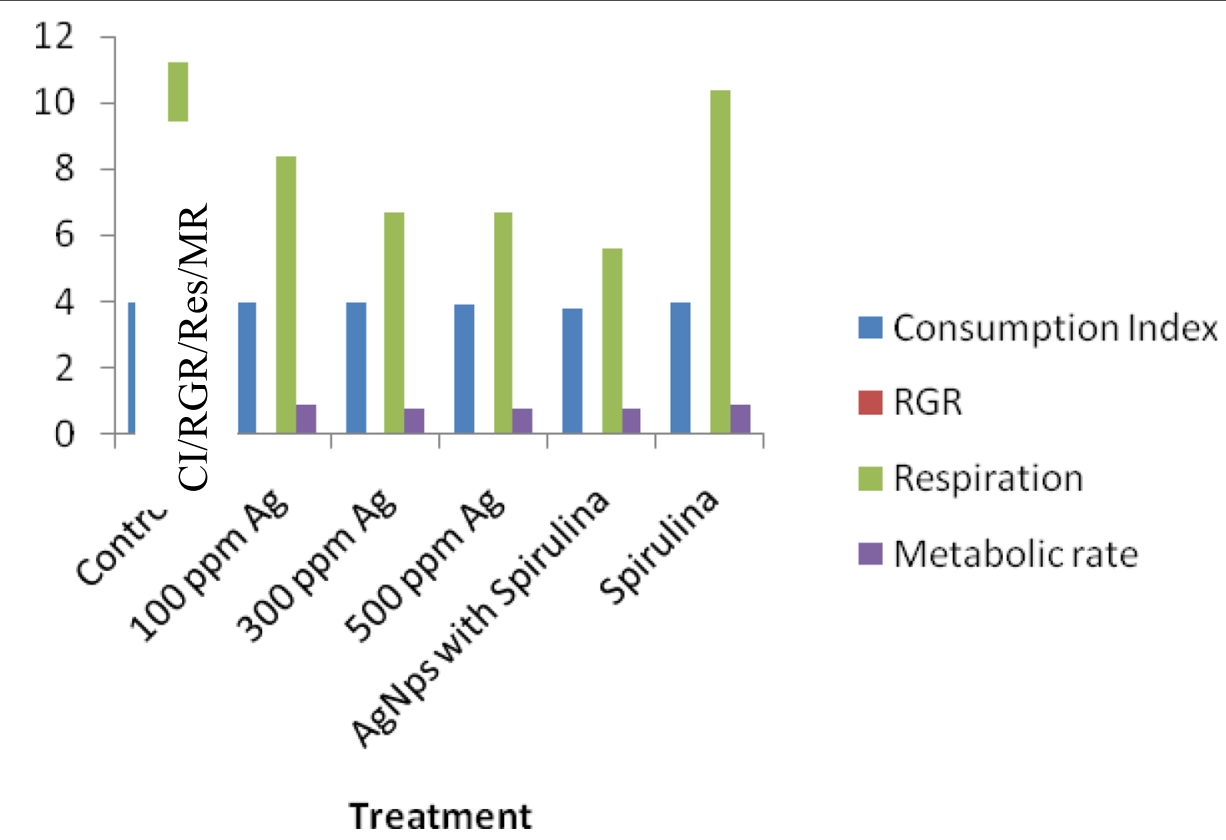

Fig. 4 Comparison of consumption Index, relative growth rate, respiration, and metabolic rate of treated silkworm groups 
Table 2 Growth rate of the fifth-instar larvae of silkworm

\begin{tabular}{|c|c|c|c|c|c|c|}
\hline Day & Control $\left(T_{1}\right)$ & 100 ppm Ag $\left(T_{2}\right)$ & $300 \mathrm{ppm} \mathrm{Ag}\left(\mathrm{T}_{3}\right)$ & $500 \mathrm{ppm} \mathrm{Ag}\left(\mathrm{T}_{4}\right)$ & AgNPs + Spirulina $\left(T_{5}\right)$ & Spirulina $\left(T_{6}\right)$ \\
\hline \multicolumn{7}{|c|}{ Length (in cm) } \\
\hline 1 & $3.7 \pm 0.00$ & $4.1 \pm 0.04$ & $4.3 \pm 0.09$ & $4.5 \pm 0.00$ & $4.75 \pm 0.09$ & $4.65 \pm 0.01$ \\
\hline 2 & $3.82 \pm 0.05$ & $4.34 \pm 0.05$ & $4.5 \pm 0.05$ & $4.75 \pm 0.09$ & $4.95 \pm 0.05$ & $4.93 \pm 0.09$ \\
\hline 3 & $4.1 \pm 0.03$ & $4.52 \pm 0.09$ & $4.73 \pm 0.06$ & $4.95 \pm 0.05$ & $5.22 \pm 0.04$ & $5.2 \pm 0.00$ \\
\hline 4 & $4.45 \pm 0.05$ & $4.63 \pm 0.09$ & $4.92 \pm 0.06$ & $5.22 \pm 0.05$ & $5.23 \pm 0.03$ & $5.35 \pm 0.09$ \\
\hline 5 & $4.9 \pm 0.05$ & $5.05 \pm 0.05$ & $5.43 \pm 0.09$ & $6 \pm 0.05$ & $6.2 \pm 0.09$ & $6.1 \pm 0.03$ \\
\hline \multicolumn{7}{|c|}{ Weight (in grams) } \\
\hline 1 & $1.3 \pm 0.00$ & $1.4 \pm 0.00$ & $1.5 \pm 0.00$ & $1.9 \pm 0.00$ & $2 \pm 0.09$ & $2.08 \pm 0.05$ \\
\hline 2 & $1.34 \pm 0.05$ & $1.42 \pm 0.09$ & $1.53 \pm 0.05$ & $1.95 \pm 0.03$ & $2.32 \pm 0.01$ & $2.2 \pm 0.09$ \\
\hline 3 & $1.4 \pm 0.00$ & $1.5 \pm 0.09$ & $1.55 \pm 0.05$ & $2.12 \pm 0.01$ & $2.25 \pm 0.05$ & $2.2 \pm 0.05$ \\
\hline 4 & $1.5 \pm 0.05$ & $1.59 \pm 0$ & $1.57 \pm 0.09$ & $2.12 \pm 0.05$ & $2.39 \pm 0.06$ & $2.35 \pm 0.04$ \\
\hline 5 & $1.6 \pm 0$ & $1.53 \pm 0.06$ & $1.6 \pm 0$ & $2.2 \pm 0.05$ & $2.4 \pm 0$ & $2.5 \pm 0.03$ \\
\hline
\end{tabular}

The results are the mean value of triplicate analysis \pm standard deviation

length $(1336 \mathrm{~m})$ and weight $(0.32 \mathrm{~g})$. Next to this, Spirulina alone-treated group produced $1307 \mathrm{~m}$ filament length and $0.30 \mathrm{~g}$ weight. AgNP-treated group produced length and weight at $1126 \mathrm{~m}$ and $0.24 \mathrm{~g}, 1238 \mathrm{~m}$ and $0.26 \mathrm{~g}$, and $1305 \mathrm{~m}$ and $0.30 \mathrm{~g}$ with the concentration of $100 \mathrm{ppm}, 300 \mathrm{ppm}$, and $500 \mathrm{ppm}$, respectively.

\section{Sericin and fibroin content}

Sericin and fibroin are two important proteins present in the silk filament with sericin forming the outer coating of the fibroin and fibroin giving luster to the silk filament. The concentration of AgNPs was increased; the weight of the sericin and fibroin content also increased simultaneously. It is noted that the sericin $(0.62 \mathrm{~g})$ and fibroin $(0.95 \mathrm{~g})$ content was double the times increased at the concentration of AgNPs with Spirulina-treated group $\left(\mathrm{T}_{5}\right)$ than the control group $\left(\mathrm{T}_{1}\right)$ had sericin $(0.32 \mathrm{~g})$ and fibroin $(0.68 \mathrm{~g})$ content.

DMRT analysis for silk gland weight, cocoon weight, silk filament weight, and sericin and fibroin content were shown in the Table 4. The data shows that AgNPs with Spirulina-treated group varied significantly when compared to the control. The $100 \mathrm{ppm}$ and $300 \mathrm{ppm}$ AgNP-treated groups are on par with each other. The 500 ppm AgNPs and Spirulina alone-treated group shows the lesser significance when compared to the AgNPs with Spirulina. Among the six treated groups, the AgNPs with Spirulina-treated group proved to be significant in economical traits.

\section{Discussion}

Applications of nanotechnology to medicine and physiology denote materials and devices designed to cooperate with the body at subcellular scales with a high degree of specificity (Sahoo, Praveen, \& Panda, 2007). The reduction of $\mathrm{Ag}^{+}$ions into $\mathrm{Ag}^{0}$ metal nanoparticles was primarily observed by the color change of the colorless to a yellow color which is confirmed by the surface plasmon resonance excitation of synthesized silver nanoparticles (Krishnakumar et al., 2015). The UV-Vis spectrum of synthesized silver nanoparticles showed strong absorbance at $422 \mathrm{~nm}$ indicating the presence of silver nanoparticles (Thangapandiyan \& Prema, 2012). From the SEM result, the morphology of the particles were observed and it was spherical in nature (Basavaraj, Praveenkumar, Sabiha, Rupali, \& Samprita, 2012). The EDS spectrum showed a strong signal at $3 \mathrm{keV}$ which is the characteristic of $\mathrm{Ag}$ (Maribel, Jean, \& Stephan, 2009).

The Lepidopteron insect (B. mori) is highly specialized for rapid growth, primarily achieved by higher rate of food

Table 3 DMRT analysis of silkworm Bombyx mori on growth rate

\begin{tabular}{|c|c|c|c|c|c|}
\hline Control $\left(T_{1}\right)$ & 100 ppm Ag $\left(T_{2}\right)$ & 300 ppm Ag $\left(T_{3}\right)$ & $500 \mathrm{ppm} \mathrm{Ag}\left(\mathrm{T}_{4}\right)$ & AgNPs + Spirulina $\left(T_{5}\right)$ & Spirulina $\left(T_{6}\right)$ \\
\hline \multicolumn{6}{|l|}{ Length } \\
\hline $4.1940^{\mathrm{A}}$ & $4.5280^{B}$ & $4.7760^{C}$ & $5.0840^{C}$ & $5.4075^{C}$ & $5.0350^{C}$ \\
\hline \multicolumn{6}{|l|}{ Weight } \\
\hline $1.4280^{\mathrm{A}}$ & $1.880^{\mathrm{A}}$ & $1.5500^{\mathrm{A}}$ & $2.0580^{B}$ & $2.2720^{C}$ & $2.2660^{C}$ \\
\hline
\end{tabular}

Capital letters represent comparison of row means. Mean values are taken for the various days of similar concentration. The highest significance is observed in the group which was AgNPs and Spirulina treated 




\section{Treatment}

Fig. 5 Cocoon shell ratio \% of the AgNPs and Spirulina-treated groups

consumption. In the present nutritional efficiency conversion among the six groups, the AgNPs with Spirulina-treated group has the lowest ingesta and highest digesta values (Chinnaswamy, Hothur, Kumar, Anuradha, \& Kumar, 2011). Consumption index and efficiency conversion of ingesta are the driving indexes in deciding efficiency of groups, and thus, in our condition, AgNPs with Spirulina-treated group expressed the best performances. As a whole, it showed the lowest ingesta and consumption index values. The conversion efficiency of ingesta to larva, cocoon, and shell were the highest, and grams of ingesta necessary to produce 1 gram of cocoon were the lowest in our test group $T_{5}$. The larval enzymatic apparatus used to convert the nutrients to body matter and, more specifically, to silk proteins were finely tuned (Rahamathulla, Mathur, \& Geethadevi, 2004).

In the present investigation, minimum food consumption index significantly increased the fifth-instar larval growth as well as good cocoon characters when exposed to different concentrations of AgNPs and Spirulina. This may be due to the nutritional supplementation (Amalarani, Padmalatha, \& Ranjith Singh, 2011). Food consumption has a direct relevance on the weight of larvae, cocoon, pupae, and shell (Shivakumar, 1995). In the present study, it has observed that the food consumption and utilization have been found to be lowered in the fourth-instar than in the subsequent stage of growth and development. In general, the present results are in agreement with the observations of earlier workers (Balasundaram, Selvi, \& Mathivanan, 2008; Rath, 2010). The approximate digestibility, reference ratio of AgNPs with Spirulina-treated group, showed an increasing trend when compared to the control. Reference ratio is an indirect expression of absorption and assimilation of food. The study results also found that comparatively higher RR values were recorded in the AgNPs with Spirulina-treated group (Ganesh Prabu et al., 2012). The food consumption index (CI) and approximate

Table 4 DMRT analysis of silkworm Bombyx mori on economical traits

\begin{tabular}{lllllll}
\hline Economical traits & Control & $100 \mathrm{ppm} \mathrm{Ag}$ & $300 \mathrm{ppm} \mathrm{Ag}$ & $500 \mathrm{ppm} \mathrm{Ag}$ & AgNPs + Spirulina & Spirulina \\
\hline Silk gland weight & $0.7500^{\mathrm{A}}$ & $0.7700^{\mathrm{B}}$ & $0.7700^{\mathrm{B}}$ & $0.8000^{\mathrm{C}}$ & $0.8700^{\mathrm{D}}$ & $0.8500^{\mathrm{E}}$ \\
Cocoon weight & $1.3000^{\mathrm{A}}$ & $1.3500^{\mathrm{B}}$ & $1.4500^{\mathrm{C}}$ & $1.7400^{\mathrm{D}}$ & $1.8400^{\mathrm{E}}$ & $1.7100^{\mathrm{F}}$ \\
Silk filament weight & $0.2200^{\mathrm{A}}$ & $0.2400^{\mathrm{B}}$ & $0.2600^{\mathrm{C}}$ & $0.3000^{\mathrm{D}}$ & $0.3200^{\mathrm{D}}$ & $0.3000^{\mathrm{E}}$ \\
Sericin content & $0.3200^{\mathrm{A}}$ & $0.5100^{\mathrm{B}}$ & $0.3300^{\mathrm{C}}$ & $0.4700^{\mathrm{D}}$ & $0.6200^{\mathrm{E}}$ & $0.5700^{\mathrm{F}}$ \\
Fibroin content & $0.6800^{\mathrm{A}}$ & $0.5700^{\mathrm{B}}$ & $0.7800^{\mathrm{C}}$ & $0.8500^{\mathrm{D}}$ & $0.9500^{\mathrm{E}}$ & $0.8600^{\mathrm{F}}$ \\
\hline
\end{tabular}

Capital letters represent comparison of row means (different concentration for a particular group) 
digestibility $(\mathrm{AD})$ varied depending upon the quality of leaf and age of the larva.

The efficiency conversion of cocoon and shell is determined by the consumption index. The present study clearly portrays this phenomenon. AgNPs with Spirulina have the lowest consumption index but they attained double the times increased relative growth rate and efficiency conversion of cocoon and shell. This drastic achievement in a particular group is because of the synergistic action of AgNPs with Spirulina. Further, it has been revealed from the present study that the tissue weight was significantly increased in the third instar. A similar trend was noticed with ECI, ECD, and RGR in the earlier reports (Alessio et al., 2014; Chinnaswamy et al., 2011). Respiration is the total oxidation of the digested or assimilated food for releasing energy required for the entire biological activities by breakdown of macromolecules into simpler molecules. Metabolic rate is the biochemical reaction involved in the degradation of macromolecules into smaller units and vice versa. Our study obtained the lowest respiration and metabolic rate in the AgNPs with Spirulina-treated group than in the control.

In the present study, the larval length and weight were significantly increased in all tested groups. The maximum increase was noticed in the $T_{5}$ group. Many researchers showed that the larval characters expand by different concentrations of corresponding complexes such as ascorbic acid, folic acid, thiamin, and vitamin B complex (Balasundaram et al., 2008; Sarker, Haque, Rab, \& Absar, 1995). Multi-vitamins and mineral compounds could increase the food consumption, growth, and alteration productivity of silkworm (Muniandy, Sheela, \& Nirmala, 1995).

Leaf consumption rate directly influences the silk-producing capacity and body weight of the silkworm (Muthukrishnan, Madhavan, \& Navarathna Jothi, 1978; Sumioka, Kunda, \& Yoshitake, 1982). Spirulina-mediated activation of tissue metabolism seems to be an essential factor for the promotion of biological parameters of silk gland of silkworm larvae (Kumar \& Balasubramanian, 2014). It is observed that the wet weight of silk gland increased significantly as compared to the control group. According to Mathavan and Krishnan (1976), assimilation efficiency did not vary significantly even at reduced food consumption. It was reported that cocoon weight and pupal weight were directly proportional to the concentration of Juvenile hormone and the feeding period (Akai, Kimura, Kiguchi, \& Shibukawa, 1985; Chowdhary, Raju, \& Ogra, 1990). In the present study, the significant increase of cocoon weight and cocoon shell ratio was achieved in the $\mathrm{T}_{5}$ group. It is due to the stimulation of AgNPs and Spirulina from the third to fifth instars, feeding more amount of nutrients intake than the control. The growth-promoting effect of proteins and vitamins are found in Spirulina, and it is treated on silkworm with vitamins and amino acids to enhance the larval and cocoon length, weight, cocoon shell, and pupal weight. The AgNPs exhibited high antimicrobial activity, and this property can be very useful, especially against microorganism resistant to conventional antimicrobials (Sharma, Yngard, \& Lin, 2009). The AgNPs entering the gut of silkworm B. mori from AgNP-treated MR2 mulberry leaves inhibit the pathogenic bacterial growth and multiplication to prevent the bacterial diseases and enhance the feed efficacy, larval growth rate, silk protein synthesis, and synergistic silk production. The specific dose of Spirulina at $0.03 \%$ concentration contains a maximum amount of essential amino acids and vitamins which determines the specificity for various metabolic activities in silkworm B. mori (Ponraj, Selvi, Veeranarayanan, \& Balasundaram, 2011).

Thyroxine hormone supplementation on silkworm could increase the economic traits like cocoon weight larval weight, pupal weight, shell ratio (\%), filament length, and sericin and fibroin content (Latha, Prema, Selvarani, \& Thangapandiyan, 2011). Thilagavathi, Selvisabhanayakam, and Ganesh Prabu (2013) prescribed that the treatment of amoxicillin antibiotic drug at the concentration of $0.4 \%$ may have beneficial effects on the growth of the silkworm larval and pupal length, width, and weight and also increased the quantity of silk production by enhancing the economic parameters than control. Similarly, the present study evidenced the AgNPs with Spirulina-treated group increased in the economic parameters such as silk gland weight, silk filament weight, silk filament length, cocoon shell ratio, and sericin and fibroin content. So, this supplementation could be prescribed to the farmers to get more quantity of silk.

\section{Conclusion}

India is the second largest producer and biggest consumer of silk. Silkworm (Bombyx mori) is the voracious feeder, the source of producing the silk. Fortification of mulberry leaves with supplementary nutrients can give the good quality and quantity of the cocoon and silk production. In conclusion, AgNPs with Spirulina could give synergistic action and more quality cocoons. Therefore, the present study prescribed AgNPs as having the potential to synthesize synergistic silk.

\section{Abbreviations \\ AgNPs: Silver nanoparticles; DMRT: Duncan's multiple range test; EDS: Energy-dispersive spectroscopy; SEM: Scanning electron microscopy; $\mathrm{XRD}$ : X-ray diffraction pattern}

\section{Acknowledgements}

The authors greatly acknowledge The Department of Zoology, PSG College of Arts and Science, for the facilities extended towards the research.

Funding

We declare that there are no funding sources. 


\section{Availability of data and materials}

All the data and materials presented in the manuscript are the original work of the authors.

\section{Authors' contributions}

DR performed the experiment. DR has written the manuscript. ST was sourced as a research supervisor and designed the work. Both authors read and approved the final manuscript.

\section{Ethics approval and consent to participate}

Not applicable.

\section{Competing interests}

The authors declare that they have no competing interests.

\section{Publisher's Note}

Springer Nature remains neutral with regard to jurisdictional claims in published maps and institutional affiliations.

Received: 2 November 2018 Accepted: 3 April 2019

Published online: 22 April 2019

\section{References}

Aashritha, S. (2013). Synthesis of silver nanoparticle by chemical reduction method and their antifungal activity. International Research Journal of Pharmacy, 4(10), 111-113.

Akai, H., Kimura, K., Kiguchi, M., \& Shibukawa, K. (1985). An increase of silk production by repeated treatment with a juvenile hormone analogue. Journal of Sericultural Sciences of Japan, 54(4), 297-299.

Akhtar, M., \& Asghar, A. (1972). Nutritional requirement of silkworm Bombyx mori. Pakistan Journal of Zoology, 4(1), 101-107.

Alessio, S., Ludovica, T., Clotilde, R., Chiara, P., Valter, C., \& Silvia, C. (2014). Rearing of monovoltine strains of Bombyx mori by alternating artificial diet and mulberry leaf accelerates selection for higher food conversion efficiency and silk productivity. Bulletin of Insectology, 67(2), 167-174.

Amalarani, G., Padmalatha, C., \& Ranjith Singh, A. J. A. (2011). Probiotic supplementation to improve commercial characteristics, disease resistance and protein in the silkworm Bombyx mori L. World Journal of Biological Research, 4(2), 12-26.

Asta, S., Igoris, P., Puiso, J., Algimantas, J., \& Asta, G. (2006). Analysis of silver nanoparticles produced by chemical reduction of silver salt solution. Materials Science, 12(4), 287-291.

Balasundaram, D., Selvi, S., \& Mathivanan, V. (2008). Studies on comparative feed efficacy of mulberry leaves MR2 and MR2 treated with vitamin C on Bombyx mori (L.) (Lepidoptera: Bombycidae) in relation to larval parameters. Current Sciences, 12(2), 677-682.

Basavaraj, U., Praveenkumar, N., Sabiha, T. S., Rupali, S., \& Samprita, B. (2012). Synthesis and characterization of silver nanoparticles. International Journal of Pharmacy and Biological Sciences, 2(3), 10-14.

Chinnaswamy, R., Hothur, L., Kumar, S. S., Anuradha, C. M., \& Kumar, C. S. (2011). Nutrigenetic screening strains of the mulberry silkworm. Journal of Insect Science, 12(3), 1-18.

Chowdhary, S. K., Raju, R. S., \& Ogra, R. K. (1990). Effect of JH analogues on silkworm, Bombyx mori L., growth and development of silk gland. Sericologia, 30(2), 155-165.

Ganesh Prabu, P., Selvi, S., Balasundaram, D., Pradhap, M., Vivekananthan, T., \& Mathivanan, V. (2012). Effect of food supplementation with silver nanoparticles (AgNps) on feed efficacy of silkworm, Bombyx mori (L.) (Lepidoptera: Bombycidae). International Research Journal of Biological Sciences, 2(2), 60-67.

Guangyu, Z., Yan, L., Xiaoliang, G., \& Yuyue, C. (2014). Synthesis of silver nanoparticles and antibacterial property of silk fabrics treated by silver nanoparticles. Nanoscale Research Letters, 9(1), 216 1-8.

Hardy, J. G., Romer, L. M., \& Scheibel, T. R. (2008). Polymeric materials based on silk proteins. Polymer, 49(20), 4309-4327.

Islam, M. R., Ali, M. O., Paul, D. K., Sultana, S., \& Banu, N. A. (2004). Effect of salt, nickel chloride supplementation on the growth of silkworm Bombyx mori (L). Journal of Biological Sciences, 4(2), 170-172.

Ito, T. (1978). In Y. Tazima (Ed.), Silkworm nutrition in the silkworm an important laboratory tool, (pp. 121-157). Tokyo: Ko. Ltd..
Krishnakumar, S., Sindu, D., Shankar, U., Prakash, G., Williums, G., \& Sasikumar, M. (2015). Extracelluler biosynthesis of silver nanoparticles (Ag-NPs) using Fusarium oxysporium (MTCC-2480) and its antibacterial efficacy against gram negative human pathogens. Journal of Chemical and Pharmaceutical Research, 7(1), 62-67.

Kumar, K., \& Balasubramanian (2014). Supplymentary effects of Spirulina on lipids and enzymes in silkgland of silkworm. Journal of Entomology and Zoology Studies, 2(4), 27282

Latha, S., Prema, P., Selvarani, M., \& Thangapandiyan, S. (2011). Growth rate pattern and economic raits of Bombyx Mori L under the influence of thyroxine treated mulberry varieties. Journal for Bloomers of Research, 4(1), 276-282.

Marek, K., Tatsiana, D., Aleksandra, M., \& Lidia, R. (2016). Certain aspects of silver and silver nanoparticles in wound care. Journal of Nanomaterials, 4(10), 1-10.

Maribel, G., Jean, D., \& Stephan, G. (2009). Synthesis of silver nanoparticles by chemical reduction method and their antibacterial activity. International Journal of Chemical and Biomolecular Engineering, 2(3), 106-111.

Martin, M. D., Kinner, J. F., \& Thomas, J. A. (1971). Developmental changes in the late larvae of Calliphora stygia. IV. Uptake of plasma protein by the fat-body. Australian Journal of Biological Sciences, 24, 291-299.

Mathavan, S., \& Krishnan, J. M. (1976). Effects of ration levels and restriction of feeding durations on food utilization in Danaus chrysippus (Lepidoptera: Daniadae). Entomologia Experimentalis et Applicata, 19, 155-162.

Mondal, M., Kanika, T., \& Nirmal, K. (2007). The silk proteins, sericin and fibroin in silkworm, Bombyx mori Linn. - a review. Caspian Journal of Environmental Sciences, 5(2), 63-76.

Muniandy, S., Sheela, M., \& Nirmala, S. T. (1995). Effect of vitamins and minerals (Filibon) on food intake, growth and conversion efficiency in Bombyx mori. Environment and Ecology, 13(2), 433-435.

Muthukrishnan, J., Madhavan, S., \& Navarathna Jothi, V. (1978). Effect of restriction of feeding duration of food utilization, emergence and silk production in Bombyx mori L. (Lepidoptera: Bombycidae). Monitore Zoologico Italiano-Italian Journal of Zoology, 12, 87-94.

Ponraj, G. P., Selvi, S., Veeranarayanan, M., \& Balasundaram, D. (2011). Studies on the growth rate of silkworm Bombyx mori (L.) (Lepidoptera: Bombycidae) fed with control and silver nanoparticles (AgNps) treated MR2 mulberry leaves. International Journal of Industrial Entomology, 22(2), 39-44.

Rahamathulla, V. K. Mathur, V. B., \& Geethadevi, R. G. (2004). Growth and dietary efficiency of mulberry silkworm (Bombyx mori) under various nutritional and environmental stress conditions. Philippines Journal of Science, 133(1), 39-43.

Rajitha, K., \& Savithri, G. (2015). Studies on symptomological and economic parameters of silk cocoons of Bombyx mori inoculated with Beauveria Bassiana (Bals.) Vuill. International Journal of Current Microbiology and Applied Sciences, 4(2), 44-54.

Ramesha, C., Lakshmi, H., Kumari, S. S., Anuradha, C. M., \& Kumar, C. S. (2012). Nutrigenic screening strains of the mulberry silkworm, Bombyx mori, for nutritional efficiency, Journal of Insect science, 12(3), 1-18.

Rath, S. S. (2010). Food utilization efficiency in Antheraea mylitta fed on Terminalia arjuna leaves. Academic Journal of Entomology, 3(1), 23-28.

Sahoo, S. K., Praveen, S., \& Panda, J. J. (2007). The present and future of nanotechnology in human health care. Nano Medicine, 3(1), 20-31.

Sarker, A., Haque, M., Rab, M., \& Absar, N. (1995). Effects of feeding mulberry (Morus sp.) leaves supplemented with different nutrients to silkworm (Bombyx mori) L. Current Science, 69(2), 185-188.

Seki, K., \& Oshikane, K. (1959). Textile and Sericulture, Shinshu University, Res. Reports. Fac.

Sengupta, K., Singh, B. D., \& Mustafi, J. C. (1972). Nutrition of silkworm, Bombyx mori (L). Studies on the enrichment of mulberry leaf with various sugars, proteins, amino acids and vitamins for vigorous growth of the worm and increased cocoon crop protection. Indian Journal of Sericulture, 11(1), 11-27.

Sharma, V. K., Yngard, R. A., \& Lin, Y. (2009). Silver nanoparticles: green synthesis and their antimicrobial activities. Advances in Colloidal and Interface Sciences, $145(1-2), 83-96$.

Shivakumar, C. (1995). Physiological and biochemical studies on nutrition in silkworm, Bombyx mori L, (p. 211). Ph. D. Thesis, Bangalore University.

Sumioka, H. S., Kunda, S., \& Yoshitake, N. (1982). Relationship among food ingestion, food digestion and body weight gain in the silkworm larvae Bombyx mori under restricted feeding by indices. Journal of Sericultural Science, 5(1), 52-57.

Thangapandiyan, S., \& Prema, P. (2012). Chemically fabricated silver nanoparticles and enhances the activity of antibiotics against selected human bacterial pathogens. International Journal of Pharma Sciences and Research, 3(5), 1415-1422.

Thilagavathi, G., Selvisabhanayakam, \& Ganesh Prabu, P. (2013). Studies on the impact of amoxicillin on growth rate and economic parameters of silkworm 
bombyx mori (I.) (lepidoptera: bombycidae) in relation to silk production. International Journal of Current Research, 5(10), 3232-3237.

Tuigong, D. R., Kipkurgat, T. K., \& Madara, D. S. (2015). Mulberry and silk production in Kenya. Journal of Textile Science and Engineering, 5(6), 1-7.

Vorobyova, S. A., Lesnikovich, A. I., \& Sobal, N. S. (1999). Preparation of silver nanoparticles by inteerphase reduction. Colloids and Surfaces $A$ :

Physicochemical and Engineering Aspects., 152, 375-379.

Submit your manuscript to a SpringerOpen ${ }^{\mathcal{O}}$ journal and benefit from:

- Convenient online submission

- Rigorous peer review

- Open access: articles freely available online

- High visibility within the field

- Retaining the copyright to your article

Submit your next manuscript at $\boldsymbol{\nabla}$ springeropen.com 